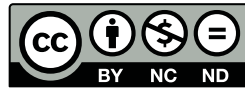

Estudos Teológicos foi licenciado com uma Licença Creative Commons Atribuição - NãoComercial - SemDerivados 3.0 Não Adaptada

http://dx.doi.org/10.22351/et.v58i1.3007

\title{
El CUERPO DE LA POBREZA: BELLEZA, FEALDAD Y JUVENTUD FEMENINA en la Iglesia Evangélica Pentecostal de Chile (1925-1950) ${ }^{1}$
}

\author{
O corpo da pobreza: beleza, feiura e juventude feminina \\ na Igreja Evangélica Pentecostal do Chile (1925-1950) \\ The body of poverty: beauty, ugliness and female youth \\ in the Chilean Pentecostal Evangelical Church (1925-1950)
}

\section{Miguel Angel Mansilla ${ }^{2}$ Constanza Vélez Caro ${ }^{3}$ Luis Orellana Urtubia ${ }^{4}$}

\begin{abstract}
Resumen: El objetivo de este artículo es conocer las condiciones e interpretaciones sobre la construcción social de belleza y fealdad de la juventud femenina existente en los relatos pentecostales entre los años 1925 a 1950. Para ello recurrimos a la revista Fuego de Pentecostes. Este artículo lo hemos dividido en tres apartados. Comenzamos escribiendo el contexto social y económico en que se desarrolla el pentecostalismo chileno; una sociedad chilena en donde los pobres, no tenían ninguna posibilidad de salir de la miseria. En segundo lugar, nos referimos a la juventud y belleza en donde se evidencia una concepción fugaz de la juventud y una negación de la belleza física: la juventud es una realidad espiritual y su existencia física es solo es un espejismo. Por último, abordamos el cuerpo femenino y el espacio de miseria. Esto se trata de la lucha en el que el pentecostalismo intenta convencer a las jóvenes sobre la futilidad de la preocupación somática, ya que la realidad social es concebida como una expoliación corpórea; por ello se insta a las jóvenes a la desafección, conminación y discordancia del cuerpo entre la realidad somática de la sociedad y la presentada por la comunidad pentecostal.
\end{abstract}

Palabras claves: Pentecostalismo. Miseria. Mujeres. Chile.

1 O artigo foi recebido em 30 de abril de 2017 e aprovado em 13 de junho de 2017 com base nas avaliações dos pareceristas ad hoc

2 Doctor en Antropología, Universidad de Tarapacá (UTA). Sociólogo, Universidad Arturo Prat. Investigador Asociado del Instituto de Estudios Internacionales, INTE.

3 Estudiante de Magíster en Antropología, Universidad de Tarapacá (UTA). Licenciada en Arte, Tecnología y Gestión Musical, Universidad de Valparaíso. Investigadora Asociada del Instituto de Estudios Internacionales, INTE.

4 Doctor en Estudios Americanos, especialidad Pensamiento y Cultura, Universidad de Santiago de Chile. Teólogo, Universidad Bíblica Latinoamericana. Investigador Asociado del Instituto de Estudios Internacionales, INTE. 
Resumo: O objetivo deste artigo é conhecer as condições e as interpretações da construção social da beleza e a feiura da juventude feminina nas histórias pentecostais entre os anos 1925 até 1950. Para isso, voltamo-nos à revista Fogo do Pentecostes. Este artigo foi dividido em três seções. Começamos por descrever o contexto social e econômico em que o pentecostalismo chileno se desenvolve; uma sociedade onde o pobre não tinha a chance de escapar da pobreza. Em segundo lugar, nós nos referimos à juventude e à beleza, onde a juventude é um conceito fugaz e a beleza física é uma negação evidente: a juventude é uma realidade espiritual e a existência física é apenas uma miragem. Finalmente, abordamos o corpo feminino e o espaço da miséria. Isto é, a luta na qual o pentecostalismo tenta convencer as jovens sobre a futilidade da preocupação com o corpo, porque a realidade social é concebida como uma desapropriação corporal; porque as mulheres jovens são encorajadas à desafeição, obediência e discordância entre o corpo e a realidade física da sociedade e pela comunidade pentecostal.

Palavras-chave: Pentecostalismo. Miséria. Mulheres. Chile.

Abstract: The aim of this article is to know about the conditions and the interpretations of the social construction of beauty and ugliness of the young woman existing in the Pentecostal stories between 1925 and 1950. To achieve this, we resort to the magazine Pentecost Fire. This article is divided into three sections. We begin by describing the social and economic context in which Chilean Pentecostalism develops; a Chilean society where the poor had no chance of getting out of misery. Secondly, we refer to youth and beauty in which a fleeting conception of youth and the denial of physical beauty are evident: youth is a spiritual reality and its physical existence is only a mirage. Finally, we address the female body and the space of misery. This is the struggle in which Pentecostalism tries to convince the young women about the futility of somatic concern, since social reality is conceived as a corporeal plunder; for this reason, the young women are urged to disaffection, condemnation and disagreement of the body between the somatic reality of society and that presented by the Pentecostal community. Keywords: Pentecostalism. Poverty. Women. Chile

\section{Introducción}

Como lo ha señalado la sociología clásica, la religión es una construcción social. En el sentido que sus doctrinas, ritos, principios teológicos, representaciones sociales y utopías, todas, tienen un sustento social-cultural moldeado y condicionado históricamente. En consecuencia, las representaciones sociales que los pentecostales manifiestan sobre el cuerpo femenino están condicionadas socialmente e históricamente situadas. Por consiguiente, determinadas representaciones sociales cumplen funciones sociales por algún periodo y pese a que la institución las sacralice, como ya no responden al contexto social, los mismos sujetos las resisten, alteran y cambian.

Desde otra perspectiva tales concepciones, por ejemplo, las creencias y prácticas somáticas de la mujer joven, pueden parecer opresivas, explotadoras y constriñentes. Sin embargo, desde la sociología de la religión, esto se interpreta como condiciones condicionadas del cuerpo femenino y que afectan su concepción de belleza y fealdad. Por lo tanto, dichas concepciones no sólo varían con el tiempo; sino 
también en el mismo contexto. Esto porque el sujeto no asume pasivamente la postura institucional, sino que la somete a negociación y a escrutinio personal. Luego puede adoptarla parcialmente antes los ojos institucionales, pero adoptándola y ajustándola a su persona y a su rol. Esto es que una mujer joven soltera puede acoger tácitamente una postura corporal en el tiempo y espacio eclesiásticos, pero agregarle un tinte personal en contextos extra-eclesiales, que, a los ojos institucionales, puede parecer rebeldía, pero para la joven sólo puede ser "ajuste personal". También una joven puede acomodarse a una postura institucional del cuerpo y del vestir, pero al asumir un rol más protagónico termina por ceñirse institucionalmente. De igual modo, una joven puede siempre resistir las recomendaciones de vestimentas, pero al casarse termina por amoldarse a su rol, ya sea de mujer casada o madre, aunque continúe siendo joven.

Por ello, pese a las condiciones limitantes de la pobreza, la miseria y su afección sobre el cuerpo del pobre; el pentecostalismo halló las formas de resistir, rebelarse y proponer creencias y prácticas corporales distintivas. De igual modo, y pese a las condiciones limitantes del contexto social e institucional, la joven pentecostal hallaba un espacio para adoptar, adaptar o soliviantar las exigencias externas sobre su corporalidad. En consecuencia, aún en las condiciones sociales más limitantes, el sujeto no está determinado; sino que siempre busca o encuentra las posibilidades para tomar decisiones.

El objetivo de este artículo es describir las interpretaciones de construcción social de belleza y fealdad de la juventud femenina existente en los relatos pentecostales entre los años 1925 a 1950. Para ello recurrimos a la revista Fuego de Pentecostes que inicia sus publicaciones en 1927. Nos interesa esta época por tres motivos: a) no existen investigaciones sobre la juventud femenina pentecostal; b) es la época de mayor evidencia y conciencia de pobreza, miseria, hambre, mortalidad infantil y enfermedades, que distintos movimientos sociales denuncian (obreros, feministas, médicos, periodismo, novelas, teatro, grupos religiosos, etc.); c) es la época donde más crece el pentecostalismo chileno.

\section{Contexto social e histórico del Chile pentecostal}

En Chile, en la década de 1930 "más de 250.000 personas viven en conventillos acosados por el hambre, la mugre y las enfermedades, donde de 8 a 10 personas duermen en una misma pieza"'. Dejando huellas ineludibles en vida de quienes viven esta desgracia. Pero este panorama indigente viene acompañado de altos índices de mortalidad, tanto, que en Chile "tenemos ciudades que son verdaderos cementerios". Son espacios, pero también tiempos, fétidos que contaminan el cuerpo y lo afean. Eran momentos en que Chile presentaba los mayores índices de mortalidad infantil de entre todas las ciudades civilizadas según Torres ${ }^{7}$. Sin embargo, dos décadas des-

5 CÓMO VIVE y muere el pueblo en los conventillos. Boletín del Movimiento Pro-Emancipación de las Mujeres de Chile. Revista La mujer nueva, Santiago: El Movimiento, año 1, n. 10, oct. 1936. p. 6.

6 MURILlO, Adolfo. La mortalidad urbana en Chile. Santiago, Chile: Roma. 1896. p. 9.

7 TORRES, Isauro. Cómo tener y criar hijos sanos y robustos. Santiago: Nascimiento, 1926. 
pués, el problema no estaba resuelto. El economista Jorge Ahumada decía en 1958, "en Chile somos un país de niños pobres". Eran tiempos en que "los conventillos son campos malditos, de la peor especie, donde la muerte hace los más tremendos estragos" . En estos lugares execrables, "muchos infelices se quitan la vida porque les falta el amparo material, y porque en los talleres y fábricas les arrancaron la fe y la esperanza, y sólo vislumbran un porvenir amargo" ${ }^{10}$. La miseria inexorable de los conventillos comenzó a fines del siglo XIX, pero se extendió hasta los años de 1960, desplazadas por las villas miserias. Observadores externos como el protestante liberal, S.G. Inman destacaba que:

Chile está muy pobre; ha hipotecado sus entradas con los "empréstitos" de los bancos norteamericanos y con la crisis económica mundial, ha aumentó la inflación y el peso chileno fue devaluado frente al dólar. En 1931 el peso chileno estaba a 8 con respecto al dólar. Ahora (1933) está a 44 con respecto al dólar ${ }^{11}$.

Por ello el salario no alcanzaba ni siquiera para comer. El padre católico Alberto Hurtado sostenía que "nuestro pueblo vive en una gran miseria" preocupaba a los observadores norteamericanos dado que "la lucha social en ninguna parte era tan intensa como en esta gentil república, agobiada de extrema pobreza, dominada por los grandes señores de la fortuna y trabajada inteligencia de escuelas que luchan por la justicia social"13. Alberto Hurtado decía: "en Chile mueren 250 recién nacidos por cada 1000 , pero en los tugurios aumenta a 450 la mortandad infantil. En una encuesta realizada a 300 tuberculosos el $85 \%$ vive en una sola pieza" ${ }^{\prime 4}$. No importaba el gobierno electo o quien asumiera el poder: Chile no podía salir de su miseria. Es así, que esto continúa pese a los esfuerzos de los gobiernos populares (1938-1952): "Chile es un país de gran pauperismo, por ello la flama de las reformas sociales arde y se extiende por el pueblo. En ningún otro país prensa han dado tal vez mayor atención a los problemas del trabajo, habitación, alimentación y salud"15.

En este contexto de miseria, hambre y muerte se desarrolla el pentecostalismo, como la "iglesia de los pobres y de los miserables" ${ }^{16}$. Una realidad que tanto para los pentecostales "como para la mayoría de la población chilena, la sociedad chilena

8 AHUMADA, Jorge. En vez de la miseria. Santiago: Pacífico, 1958. p. 34.

9 SIERRA, Luis; MOORE, Eduardo. La mortalidad de los niños en Chile. Valparaíso: Central, 1895. p. 10.

${ }^{10}$ MARÍN, Eugenia. Condiciones del trabajo de la obrera. Relaciones y documentos del Congreso Mariano Femenino: celebrado en Santiago de Chile, julio de 1918: para conmemorar el Centenario de la Proclamación de la Virgen del Carmen como Patrona Jurada de la República y de su Ejército. Santiago: Esc. Tipo. La Gratitud Nacional, 1918. p. 399.

${ }^{11}$ SAMUEL GUY, Inman. América Revolucionaria. Conferencias y ensayo. Madrid: Morata, 1933. p. 118.

${ }_{12}$ HURTADO, Alberto. ¿Es Chile un país católico? Santiago: Los Andes, 1941. p. 46.

13 SAMUEL GUY, Inman. América Latina e sua importância mundial. São Paulo: Atlas, 1945. p. 146.

${ }^{14}$ HURTADO, 1941, p. 55.

${ }^{15}$ SAMUEL GUY, 1945, p. 368.

${ }^{16}$ D'EPINAY, Christian. El refugio de las masas: estudio sociológico del Protestantismo Chileno. Santiago, Chile: Pacifico, 1968. p. 177. 
era el mundo de la miseria, de la enfermedad y de la muerte"17. Para D'Epinay, parafraseando a Marx:

El pentecostalismo es la expresión de la miseria real; y la protesta contra esa misma miseria. Es el suspiro de la criatura fatigada, el sentimiento de un mundo sin sensibilidad, el espíritu de los tiempos privados de espíritu ${ }^{18}$.

Por ello la expresión cúltica del pentecostalismo es el éxtasis y la catarsis como una forma descargar y purificar el cuerpo de esa miseria. No obstante, el culto no estaba limitado a los templos, sino también era extensivo a las calles, plazas y caminos. "Un lema destacado es Chile para Cristo. Grupos de hombres y mujeres jóvenes e incluso adultos van hacia las carreteras y caminos para obligar a los pecadores a venir a Cristo ${ }^{19}$. Y cuando encontraban personas que no tenían dónde vivir las llevaban a sus casas: "entre estos actos de caridad que practican los hermanos, se puede contar el llevar a su propia casa a los que han convertido en la cárcel y allí lo tienen gratuitamente hasta que han encontrado trabajo" ${ }^{20}$.

Los pentecostales invirtieron la miseria, pobreza, hambre y fealdad en una dicotomía entre lo material y lo espiritual, lo profano y lo sagrado, y el cuerpo y el espíritu. La Biblia se constituyó en el alimento fundamental del espíritu, donde lo relevante no es el hambre física sino el hambre espiritual y donde lo significativo no es la alimentación sino el ayuno. La miseria física y material se constituye en riqueza espiritual. Esto vino a ser significativo en momentos en que el obrero chileno vive con hambre, pues el espacio social dejaba huellas indelebles en el cuerpo y en la mentalidad. Las condiciones históricas transformaron la mentalidad pentecostal sobre el cuerpo en un desencantamiento somático, vinculando el feísmo al cuerpo y lo bello sólo al espíritu. Este desencantamiento fue enfocado al cuerpo femenino, el más afectado por la miseria, el hambre, el dolor y la muerte, ya que al hombre se le permite socialmente la huida social y psicológica de su miseria a través del alcohol. En cambio, la mujer está condenada a vivir su miseria con lucidez y, de este modo, la religión se constituye en un aliciente frente a esa miseria y el agobio de la lucidez ante tal desolación.

Las condiciones de miseria afectan el cuerpo, pero también a las concepciones de belleza y fealdad. Como destaca Ivelic, lo bello está asociado con las ideas de bondad y orden, mientras que la palabra "feo" - que proviene del latín foedus, fétido, impuro- se asocia a la maldad y al desorden. Así lo bello y bonito se asoció a los sentidos de la vista y del oído, mientras que lo feo al olfato ${ }^{21}$. El hecho de que las personas vivan en un barrio pobre, rodeado por la miseria, el hambre y la mugre tiene una fuerte incidencia en las consecuencias y representaciones sociales del cuerpo.

\footnotetext{
17 D'EPINAY, 1968, p. 158.

18 D'EPINAY, 1968, p. 168.

19 FRODSHAM, Stanley. With signs following. The story of the Pentecostal revival in the Twentieth Century. Springfield, Missouri: Gospel, 1946. p. 186.

${ }^{20}$ HURTADO, 1941, p. 85.

${ }^{21}$ RADOSLAV, Ivelic. Obra de Arte y Experiencia de lo bello. Aisthesis, n. 27, 1994. p. 10.
} 
En este sentido el pentecostalismo de esta época, dadas las condiciones de miseria y pauperización que vivía la sociedad chilena, manifiesta una concepción desencantada de la belleza juvenil femenina; Por un lado, concibe la belleza de las mujeres jóvenes pobres como una ilusión pasajera marcada por la desnutrición y la explotación laboral. Por otro lado, se trataba de una belleza afectada por el contexto de abyección que vivía el pobre en la sociedad chilena. Frente a esta desesperanza física, se concebía el cuerpo de la mujer como un espacio determinado por la miseria, que le succionaba a la mujer esa rozagante lozanía. Por tanto, empujaba a ésta, a manifestar indiferencia frente a belleza corporal, debía embozar el cuerpo para cubrir toda sensualidad y eroticidad y transformar el cuerpo en un templo ataviado y oculto, preparado para el dolor del hambre, el trabajo y la maternidad.

\section{La juventud: una belleza ilusa}

La cultura somática pentecostal quedó fuertemente marcada por las condiciones misérrimas del espacio. Bajo estas condiciones, el cuerpo es concebido como un espacio residencia que representa las habitaciones pobres, rigurosas e inhóspitas de los pentecostales. Pero también, el cuerpo es templo sombrío, ominoso y abyecto de los pentecostales. A diferencia del protestantismo que eligió el ascetismo, la miseria eligió al pentecostal: la inclemencia no es su elección sino su condena. Son momentos en que "Chile ocupa el primer lugar en América Latina sobre mortalidad general"22. ¿Quién podría quedar indiferente frente a un panorama tan espeluznante? Frente a este panorama espantoso, el pentecostalismo hace un constante llamado a no centrarse en el cuerpo sino en el espíritu, en la muerte y no en la vida, en el cielo y no en la tierra, en lo feo y no en lo bello. La vida es nada y el mundo es suciedad. ¿Por qué? Porque no se podía ser ciego e indiferente cuando "el pueblo muere en el fondo de estos tugurios" 23 y con una de las peores muertes, que es el morir de hambre.

\section{La belleza oscura}

De este modo, la prédica pentecostal -marcada por condiciones de desnutrición, explotación laboral y la miseria-, instruye constantemente a las jóvenes a no embellecerse, sino a afearse. Porque la vida era fea, el mundo era repugnante. Era la ontología de lo putrefacto y lo infecto. Ante la dureza y la crudeza de la vida se insiste en que la juventud del pobre (es decir cuando se tiene una juventud, si es que la miseria no se la ha arrebatado antes) dura muy poco. Para el pobre no hay belleza, sólo fealdad, porque el cuerpo no es sólo una construcción social, es también una diapositiva simbólica del espacio:

22 ALLENDE, Salvador. La realidad médico-social chilena. Ministerio de Salubridad, Previsión y Asistencia Social. Santiago, Chile: Lathrop, 1939. p. 19.

${ }^{23}$ LA MUJER NUEVA. Santiago: El Movimiento, año 1, n. 10, oct. 1936. p. 6. 
[...] Generalmente la juventud vive muy preocupada de su belleza exterior; quisiéramos ser lo mejor posible; y he oído con frecuencia que la cara es el reflejo del alma, pero he observado que no siempre guarda relación el rostro con los sentimientos íntimos. Las puras y sanas costumbres, un alma justa y delicada; un corazón recto y sensible son bellezas que renacen y se conservan nuevos perennemente. La juventud vuela llevándose todos nuestros encantos físicos que pudiéramos haber poseído y nos queda sólo el recuerdo ${ }^{24}$.

Dada la rauda caducidad de la juventud y la belleza, se enfatiza sólo y únicamente la preocupación por la belleza espiritual. Porque "¿cómo puede haber belleza en que los niños desfilen desde el vientre materno al cementerio"?25. Por ello, solo hay belleza en lo espiritual, porque ella es interna e inmaterial. Sin embargo, las jóvenes siguen preocupándose de la belleza física, porque "entre los atributos del género femenino, lo bello ha ocupado desde tiempo inmemorial, un lugar privilegiado en la conformación de la identidad"26. Por lo tanto, las mujeres jóvenes pentecostales, a pesar de la fea miseria, igualmente se preocuparán e interesarán por la belleza física, pese a que se le insta a lo feo.

Las mujeres pentecostales, y sobre todo las jóvenes, no son seres pasivos, sino que se resisten y rebelan a los parámetros de bellezas promovidos por la comunidad religiosa. Aunque la belleza y la juventud sean efímeras, vale la pena intentar extenderla. Aunque haya que disfrutarla sólo por un momento, sigue valiendo la pena, disfrutar del presente antes que llegue el futuro borrascoso.

Ante esta resistencia y rebeldía de la juventud femenina, hay que vigilarlas, controlarlas y exhortarlas constantemente, haciéndoles entender que "la mujer es condenada a la miseria; partiendo del hecho de que el salario de un padre no alcanza para la manutención de la familia"27. Tampoco alcanza, aunque la mujer trabaje, porque su sueldo es la mitad del de un hombre, aunque ella trabaje más. La mujer pobre está condenada a la miseria, en consecuencia, a una fea existencia. El pentecostalismo proyecta el feísmo de la miseria de los conventillos y los barrios sin urbanizar al cuerpo femenino. Más aún cuando en "estos tugurios languidece la vida de miles de familias de obreros" 28 , en donde la mujer pasa la mayor parte de su tiempo. Por ello no hay que preocuparse de la "belleza exterior" porque no la hay, y si la hay es sólo por un momento, es una ilusión que pronto volará. La realidad son los "cuerpos desnutridos, caras pálidas, mujeres desastrosas y enfermas" 29 . Si en algún momento hay juventud y belleza, ésta es exigua. A pesar de que lo único bello existente en el barrio sean las

\footnotetext{
${ }^{24}$ FUEGO DE PENTECOSTES. n. 99, diciembre de 1936. p.10.

25 VERGARA, Marta. Necesidades del control de los nacimientos: el problema del aborto y la mujer obrera. Revista La mujer nueva, Boletín del Movimiento Pro-Emancipación de las Mujeres de Chile, Santiago: El Movimiento, año 1, n. 4, feb. 1936. p. 1.

${ }^{26}$ SOLORZA, Susana. Belleza y abyección: la representación del cuerpo femenino en la narrativa de Silvina Ocampo. Revista Espacio, Universidad de Buenos Aires, n. 42, 2009. p. 109.

27 VERGARA, 1936, p. 1.

28 LA MUJER NUEVA, 1936, p. 6.

${ }^{29}$ LA MUJER NUEVA, 1936, p. 6.
} 
jóvenes, esto es transitorio. Pero como los jóvenes cándidos, no son realistas, ellos no caminan sino "que vuelan", por lo tanto, hay que aterrizarlos, haciéndoles entender que "el pueblo muere, sumido en el abandono y la miseria más atroz" ${ }^{30}$. Nadie se preocupa, porque el mundo es malo y la sociedad es suciedad. La belleza perdurable sólo puede encontrarse en el espíritu: todo lo demás es vanidad.

\section{El espejismo de la belleza}

La belleza física y material es sólo una ilusión óptica en la que los deseos lejanos e inexistentes aparecen reflejados en la realidad de la fealdad, como si se estuviera contemplando algo bello, cuando en realidad, no existe. Sólo existe la fea miseria, esa vida rodeada de deyección. Una vida así es un légamo donde el pobre ha sido arrojado. Lo único bello existente y perfectible es la belleza espiritual, pero que no se ve a simple vista. Pero lo feo es tan preeminente que se infiltra al espíritu para mancillarlo.

No vale la pena, por lo tanto, darle mayor importancia y preocuparse de cultivar una belleza tan ficticia, sino ocuparse en conquistar las virtudes del alma, que viven y nos hacen vivir eternamente. Con nuestra belleza exterior podemos impresionar bien o agradar a las gentes; con un alma hermosa podemos agradar a Dios y a las gentes ${ }^{31}$.

La belleza física no "vale la pena" porque es volátil y una ilusión. Todo lo real es feo y todo lo feo es real. Sólo lo espiritual es bello. La miseria hace al ser humano feo, a pesar de que la fealdad no es algo inherente a éste, sino la belleza. Hay seres bellos como los niños. Pero el hambre, la mugre y la enfermedad afean lo bello. La juventud, es lo otro bello, pero es pasajera. Las mujeres jóvenes son bellas, pero les espera un mundo de dolor y fealdad. Mientras la belleza es breve, la fealdad dura toda la vida, y cada momento y espacio lo recuerda: basta con observar las viviendas que "son piezas oscuras, mal olientes, llenas de mugre, acequias descubiertas y agua putrefacta. Niños revolcándose en el barro; aire irrespirable, pocas llaves de aguas, ningún baño: toda miseria" ${ }^{32}$. También lo eran los templos, generalmente llamados por la prensa de malolientes e indecorosos.

El trabajo era otro espacio feo, marcado por la explotación y la opresión. El trabajo era una condena de la vida en donde el pan se gana con sudor y sangre, aunque lo peor era la escasez, que no permitía satisfacer el hambre. Era dicho, "el trabajador chileno invierte en su alimentación y la de su familia, un $90 \%$ de su salario, pero él está mal nutrido y la mayoría de la población sufre de hambre fisiológica" ${ }^{33}$. El cuerpo del obrero es sólo energía que succiona el patrón, ya sea en el campo o en la ciudad, en el norte o en el sur. En el campo, "al lado de las grandes casonas hacendales, con

${ }^{30}$ LA MUJER NUEVA, 1936, p. 6.

${ }^{31}$ FUEGO DE PENTECOSTES, 1936, p. 10.

${ }^{32}$ LA MUJER NUEVA, 1936, p. 6.

33 ALLENDE, Salvador. La realidad médico-social chilena. Ministerio de Salubridad, Previsión y Asistencia Social. Santiago. Chile: Lathrop, 1939. p. 38. 
parques diseñados por paisajistas franceses, de lagunas y kioscos donde se tomaba el té, se encontraban los ranchos más insalubres. Una combinación monstruosa de afrancesamiento y esclavismo ${ }^{34}$. En el norte el patrón del salitre, hacía que "el trabajador, gaste su esfuerzo físico, sudor y su energía sin ganar nada, sólo una prematura muerte" 35 . De igual forma, en el sur el patrón del carbón, "agota las fuerzas del obrero, luego lo arroja de la mina como la araña arroja fuera de su tela el cuerpo exangüe de la mosca que le sirvió de alimento. Así el destino del obrero será siempre trabajar, padecer y morir" 36 .

¿Vale la pena preocuparse por la belleza del cuerpo? ¿Tiene sentido la belleza corporal en medio de tanta fealdad y miseria? No. Es mejor desplazar esa tristeza hacia la búsqueda de la belleza del alma, la belleza espiritual. ¿Cómo se logra esto? Transformando la pena que genera el hambre en ayuno, la tristeza de la falta de ropa en hermosear y blanquear las vestiduras del espíritu; el hacinamiento y la falta de camas para dormir, en vigilias. Así el hedor de la miseria es transformado por las comunidades religiosas en medicina analgésica exhalada en la catarsis en el éxtasis, tan requeridos por sus feligreses, pero despreciados por los intelectuales, quienes consideran estas manifestaciones como negaciones de su realidad y del llevar a cabo revoluciones sociales y políticas. Pero cuando hay hambre se ancla hasta en los huesos, y no hay fuerza para revoluciones, sólo se busca mitigarla, porque se ha constituido en una carpanta que quita la vida.

\section{El cuerpo de la mujer: espacio de miseria}

Así como ha existido el arte de embellecer y de elaborar distintos tratados de belleza, los patrones, los políticos y los arrendatarios poseen el arte de deslucir la vida del pobre. Este arte del afeamiento se puede observar cuando se hacen perdurables "los conventillos en donde las personas viven en medio de la miseria y el hambre, son los cuadros más tristes de la existencia" $"$.

Si el mundo tiene sus técnicas de embellecimiento y de afeamiento, el pentecostalismo también recurre a las hormas de belleza y fealdad, para adecuarse a un molde de la perfección espiritual. Así como era necesario recurrir a prácticas correctoras y, entre ellas se encontraban "los regímenes de adelgazamiento y el empleo del corsé para modelar las formas"38, de igual forma, para la belleza espiritual se

\footnotetext{
34 BENGOA, José. Haciendas y Campesinos. Historia Social de la Agricultura Chilena Tomo II. Haciendas. Santiago, Chile: SUR, 1990. p. 12.

${ }^{35}$ GALVES, Pedro. Trabajos y antecedentes presentados al Supremo Gobierno de Chile por la Comisión Consultiva del norte. Recopilados por encargo del Ministerio del Interior por Manuel Salas Lavaqueý. Santiago de Chile: Cervantes, 1908. p. 858.

${ }^{36}$ LILLO, Baldomero. Obras Completas. Hugo Álvarez Ignacio y Bello (Ed.). Santiago, Chile: Universidad Alberto Hurtado, 2008. p. 108.

${ }^{37}$ CÓMO VIVE y muere el pueblo en los conventillos. Boletín del Movimiento Pro-Emancipación de las Mujeres de Chile. Revista La mujer nueva, Santiago: El Movimiento, año 1, n. 10, oct. 1936. p. 1-2.

38 SOLORZA, 2009, p. 110.
} 
establecen pautas, moldes de perfeccionamiento y prácticas correctoras para adornar el espíritu.

\section{Cuerpos expoliados}

La pobreza de la mujer despojaba su belleza, desgarraba su vitalidad y le quitaba la alegría. Se transformaba en un ser rendido al sufrimiento y al dolor de ver sufrir a sus hijos y su familia, al no poder alimentarlos, ni vestirlos. Pero el pentecostalismo revierte el sacrificio:

La Biblia ruega a presentar nuestros cuerpos en sacrificio vivo, santo, agradable al Señor. Las revistas de moda ruegan a las mujeres y jóvenes a presentar sus cuerpos más o menos al mundo. Un cuerpo presentando al mundo no puede ser agradable a Dios. Dios no puede participar en ninguna cosa con el mundo ${ }^{39}$.

Que el pentecostalismo enfatice el sacrificio del cuerpo en esta época es un eufemismo que sirve para dar sentido al sacrificio vivido y experimentado. Es transformar el sacrificio impuesto socialmente en una oblación sagrada. La vida "en los conventillos es hambre y enfermedad en todo su apogeo, en toda su dolorosa desnudez. Niños que lloran, madres que piden pan para sus hijos, vidas consumidas en plena juventud"40. Es necesario así, transformar los templos en espacios de liberación y descarga, lugares de llanto y lágrimas para que los explotados pudieran soportar esa fétida fealdad, sobre todo la carestía de los alimentos básicos del pobre como el pan, la leche y el azúcar. En tal contexto, el pentecostalismo ayudaba a aderezar la vida con lágrimas y el cuerpo con comidas comunitarias.

Ante el contexto de miseria se enseñaba que la mujer joven debía tratar su cuerpo con crudeza y dolor, dado que "el pueblo se ve obligado a disminuir su consumo de alimento, a restringirlo en forma tal que ya no se puede decir que se alimente, sino que ni siquiera calma su hambre" ${ }^{41}$. Esta crudeza aumentaba:

El drama de la mujer trabajadora que pasea su miseria por las calles con un niño tomado de la mano, otro de los brazos, dos siguiéndoles más atrás y generalmente otro en el vientre y llega a su casa sólo para darle una taza de té o agua caliente como único alimento para las 24 horas $^{42}$.

Hay que preparar el cuerpo de la mujer joven para una vida patibularia, en donde todo juega en contra. Si la niñez es dura y la juventud efímera, pronto llegará la maternidad, en donde el dolor del parto, no será un dolor menor ya que "la excesiva

\footnotetext{
${ }^{39}$ FUEGO DE PENTECOSTES, n. 12, diciembre de 1928. p. 12.

${ }^{40}$ CÓMO SE VIVE en los conventillos de Valparaíso. Revista Zig-Zag, Santiago, n. 691, 18 mayo 1918. p. 2.

41 VERGARA, 1936, p. 1.

42 VERGARA, 1936, p. 1.
} 
mortalidad infantil, son las lágrimas calientes que queman la mejilla de las madres”43. No obstante, los pentecostales se sentían especiales, porque al menos Dios estaba con ellos, a pesar que Dios era un padre castigador y severo. Severidad que se manifestaba en el trato con el cuerpo, pero les daba libertad a través del Espíritu Santo, para ser consolados y tener la esperanza de una vida mejor para el pobre y de castigo eterno para los opresores y explotadores.

\section{Cuerpos desafectos}

A la mujer se le enseñaba a manifestar indiferencia frente a su cuerpo: indiferencia frente a la comida, la vestimenta, el dormir y la habitación; lo importante no es lo material, sino lo espiritual. El ayuno era una táctica espiritual que servía como estrategia para enfrentar el hambre. La vida era vida era una guerra a muerte para ganar la comida, habitación y harapos.

Una manera de vestir que presenta el cuerpo al mundo es un vestuario mundano un cuerpo que viste un vestuario mundano es un cuerpo mundano. Un cuerpo mundano no puede ser aceptado por Dios, ni ser transformado por Cristo, ni vestir el vestido de boda que Cristo dará al cuerpo transformado $[\ldots]^{44}$.

Son las mujeres las que más asisten a los templos; mujeres pobres donde existe la idea que la cantidad de niños la decide Dios. Pese a que "la maternidad para la madre pobre es una maldición en una sociedad del hambre"45, los pentecostales contaban con la comunidad. Dado que "la miseria del pueblo es grande; a muchas mujeres se le seca la leche de los pechos antes de tiempo, por las pesadumbres, y no hay leche para los bebes que gritan de hambre" ${ }^{" 46}$. Entonces la comunidad ayudaba con comidas o paquetes alimenticios. Pero también estaba la simbología, porque la Biblia es pan y leche. Existían otros momentos tristes, en que el consuelo trágico era que al ser la vida muy cara y en la usencia de alimentos, la muerte significaba una boca menos que alimentar con un niño muerto en la voluntad de Dios ${ }^{47}$. Para los pentecostales estaba la posibilidad de la sanidad y el milagro, y si esto no funcionaba, estaba el acompañamiento y el consuelo de que pronto verían y reconocerían a sus hijos en el cielo. La muerte era un estado de liberación del hambre.

En los templos abundan las mujeres adultas ${ }^{48}$, $-\mathrm{y}$ entre las mujeres mayor cantidad de señoritas-, más que jóvenes varones. La mujer pentecostal debía diferenciarse del resto en el trato con el cuerpo: debía elaborar sus propias vestimentas,

${ }^{43}$ MURILLO, Adolfo. La mortalidad urbana en Chile. Santiago, Chile: Roma, 1896. p. 13.

${ }^{44}$ FUEGO DE PENTECOSTES, n. 12, diciembre de 1928. p. 12.

45 VERGARA, 1936, p. 1.

${ }^{46}$ MURILLO, 1896, p. 16.

47 SIERRA; MOORE, 1895.

48 WILLEMS, Emilio. Followers of the New Faith: Culture Change and the Rise of Protestantism in Brazil and Chile. Nashville, Tennessee: Vanderbilt University Press, 1967. 
pero también debían presentarse limpias, tanto ella como sus hijos y su marido, en el templo. Aunque esto es una constante de los pobres ya que, la inversión del obrero en vestuario era menor que en alimentos ${ }^{49}$. Pero la juventud se resiste y prefiere elaborar su belleza corporal a través de la moda. Manifiestan su preocupación constante por la moda. ¿Por qué? Quizás es, como dice Navarro, "porque la mujer se entrega más vivamente a la moda para añadir a su vida algún atractivo. Y esto no sólo para encontrar ellas mejor sabor a la existencia, sino también para que los demás las encuentren a ellas más sabrosas" ${ }^{\prime 50}$. Porque los jóvenes, como todo ser humano, se resisten a la idea de que la vida es miseria y muerte, y aunque sea por un momento, se ilusiona de la posibilidad del bienestar o bien soñar con un mundo de pan, vivienda y vestimenta asegurada.

Hablamos de un reconocimiento social en base a los criterios de belleza vigentes $^{51}$. A pesar de ser esto una preocupación estéril, dado que "uno de los grupos sociales más necesitados es sin duda el de la joven obrera. Sus escaseces y sus penas, sus peligros y sus pruebas, las grandes injusticias y las explotaciones inicuas de que es víctima, conmueven 1os corazones de 1 os que cerca de ellas han podido conocerlas" ${ }^{92}$.

\section{Cuerpo discordante}

Por otro lado, la joven pentecostal, pese a la miseria y la pobreza, pese al apresuramiento de su cuerpo, debía andar con ropa limpia, bañada, arreglada y tapada. En la limpieza de su cuerpo debía mostrar el cambio de vida, debía evidenciar ser una mujer nueva y diferente: “[...] Las mujeres cristianas tendrán que escoger entre Cristo y el mundo. Si eligen de agradar al mundo no pueden agradar a Cristo, y si eligen agradar a Cristo no pueden agradar al mundo." ${ }^{153}$. Que las jóvenes mujeres pentecostales tuvieran que elegir entre Cristo y el mundo, implicaba su asistencia permanente al templo, escapando por un momento de su miserable realidad, dado que "en los conventillos se huele la muerte" ${ }^{4}$. En el templo por lo menos había "olor a vida", una comunidad en donde podía encontrar consuelo y esperanza.

Pese a esta miseria las mujeres jóvenes luchan por revertir el realismo y la normativa pentecostal sobre el cuerpo. Esto está en consonancia con la primera mitad del siglo XX, que representó para la mujer un campo de lucha en distintos frentes desde lo político hasta la individualidad somática. Esta lucha también afectó a los grupos religiosos, los más resistentes frente a los cambios. Paulatinamente se gestó:

49 ALLENDE, 1939, p. 51.

${ }^{50}$ NAVARRO, Claudia. Las damas porteñas y la moda 1830-1930. ¿Y todas querían ser reinas? Revista del Archivo Histórico Patrimonial de Viña del Mar, año 3, n. 4, 2002. p. 10.

${ }^{51}$ SOLORZA, 2009, p. 109.

${ }^{52}$ MARÍN, 1918, p. 399.

${ }^{53}$ FUEGO DE PENTECOSTES, 1928, p. 12.

${ }^{54}$ CÓMO SE VIVE en los conventillos de Valparaíso. Revista Zig-Zag, Santiago, n. 691, 18 mayo 1918. p. 2. 
(Una) reconciliación entre el cuerpo y el alma femenina, que permitió la adquisición de una nueva definición de belleza. De la época decimonónica se heredarían características como la sobriedad y el recato que, adaptadas a las nuevas tendencias de moda, apuntarían esencialmente al des-ocultamiento del cuerpo femenino ${ }^{55}$.

La juventud es la única etapa de libertad y decisión con la que cuenta una mujer en la sociedad.

\section{Cuerpo conminado}

El cuerpo de la joven pentecostal debía ser el emblema de su identidad en su forma de vestir, caminar y tratar con los demás, sin coqueteos, y ser indiferente al galanteo masculino, sobre todo si el hombre no es evangélico. La identidad religiosa además debe enfatizar la diferencia en los géneros: "la mujer de Dios" y "el hombre de Dios":

La palabra de Dios nos enseña que es abominable que el hombre se vista de mujer y la mujer se vista de hombre, esta enseñanza es de Moisés, y el gran apóstol Pablo, dice "que es vergonzoso a la mujer cortarse el cabello o raparse; y dice la naturaleza misma, ¿no os enseña que el varón le es deshonroso dejarse crecer el cabello? [... $]^{56}$

La comunidad obliga a las mujeres usar faldas, cabello largo y sin bisutería. Las "mujeres de Dios" o "mujeres pentecostales" son distintivas en las calles y en cualquier lado por su forma de vestir. El cuerpo desnudo sólo es permitido en la intimidad del matrimonio para el caso de hombres y mujeres. De esta manera, existe una discrepancia genérica en el conocimiento y uso del propio cuerpo. Dado lo expuesto, surge la pregunta de ¿por qué las mujeres pentecostales aceptan el control y la vigilancia sobre su cuerpo? Alguien quizás podría decir que las mujeres no tenían opción ni posibilidad a la resistencia; sin embargo, a pesar de que no todas las mujeres que se convertían eran muy pobres, las mujeres aceptaban vincularse a una comunidad tan restrictiva hacia su género.

Pero la sociedad o el mundo no presentaban mejores opciones para ella. Tenía que salir a trabajar o quedarse en casa, muchas veces viviendo una doble expoliación, porque "el trabajo a domicilio es lo único que la mujer puede hacer para no abandonar sus hijos y constituye la explotación más ignominiosa" $" 57$. Pero la comunidad pentecostal también tenía una alta exigencia con los hombres: a) Exige la domesticación y feminización de la masculinidad integrándose como cabeza del hogar, legitimado por Dios en la Biblia y enfatizado por la comunidad; esto significaba dejar el alcohol y entregar el dinero ganado en su trabajo a su familia y no perder el trabajo por culpa de su embriaguez; b) Dejar de ser violento con su esposa e hijos y ser un modelo para

\footnotetext{
${ }^{55}$ NAVARRO, 2002, p. 4.

56 FUEGO DE PENTECOSTES, 1928, p. 12.

57 VERGARA, 1936, p. 1.
} 
sus descendientes varones, que en ese tiempo eran bastante numerosos, además, ser un hombre hacendoso y presencial ${ }^{58}$. La conversión del hombre al pentecostalismo traía ventajas para la mujer y la familia. Ante estos beneficios, la mujer aceptaba y enseñaba a otras mujeres el sometimiento a su esposo, por los beneficios que traía a su familia, a largo plazo, ya que una de las pocas instituciones que lograba hacer algo concreto con los hombres populares era el pentecostalismo.

Frente a un contexto social e histórico tan misérrimo, sólo quedaba esperar la pronta venida de Cristo y prepararse para la muerte; mientras tanto predicar a todos cuando se pueda. El pentecostal vive con estas ganas de morir, aunque le está vedado el suicidio, porque si llegara a terminar con su paupérrima vida, le espera el infierno. Si esta vida ya era un infierno, el otro era peor porque era eterno. Esto puede parecer de un determinismo, no obstante, el pentecostalismo encontró la posibilidad de reunirse la mayor cantidad de veces en la semana con cultos de extensos horarios; de esta manera las personas tenían la posibilidad de enfrentar, aunque sea por momentos su miseria. Por ello también muchos pentecostales ofrecían sus viviendas para transformarlas en improvisados templos, en los que pudieran albear su miseria. Por ello el pentecostalismo fue una religión de los pobres, pero no sólo para consolarlos, sino también para resistir, protestar y promover un mundo invertido de miseria, en donde los pobres se constituyen en seres humanos respetables y respetados.

Sin embargo, pese al consenso que generaba que el pentecostalismo era el único grupo protestante que crecía en Chile gracias a ser una religión de los pobres, y por lo tanto un culto organizado. Según la cultura de la pobreza, pensadores protestantes señalaban de manera pesimista que:

Sin embargo, todos los criterios de este movimiento se unen al declarar que ha producido en muchos casos resultados regeneradores inusuales y que sus trabajadores y sus partidarios son los más autosuficientes y enérgicos de todos. [Pero] el movimiento [pentecostal] ha llegado probablemente a su clímax, ya que no se han logrado ganancias en los últimos años. Parecería que en poco tiempo el campo se habrá quemado y el movimiento se apagará ${ }^{59}$.

No obstante, faltaría otra etapa de una mayor miseria, que fue durante la dictadura (1973-1989) donde el pentecostalismo vuelve a crecer. En consecuencia, durante el siglo XX, el pentecostalismo crece en los tiempos de miseria y pobreza 1925-1950; 1973-1989, mientras que, en los momentos de aumento de las expectativas de trabajo, bienestar social y expectativa de movilidad social, el pentecostalismo se estanca. Por lo tanto, éste, no sólo ha sido protesta simbólica contra la miseria, sino también una expresión real de ella.

\footnotetext{
58 WILLEMS, 1967.

59 BROWNING, Webster; RITCHIE, John; GRUBB, Kenneth. The West Coast Republics of South America. Chile, Perú and Bolivia. London: World Dominion, 1930. p. 48.
} 


\section{Apreciaciones finales}

El cuerpo es espacio que ocupa un lugar, pero también el espacio ocupa el cuerpo. El cuerpo también ocupa un tiempo y el tiempo ocupa el cuerpo. En ese sentido, entre cuerpo, lugar y temporalidad se da una relación donde la espacialidad se vuelve social, y la corporalidad se torna espacialidad y temporalidad. Esta relación está mediada por la cultura y, por lo tanto, afectada por el espacio-temporal a través de la alimentación, la vestimenta, la vivienda, lo lúdico, lo erótico y lo sagrado.

En momentos de alta mortalidad infantil, miseria social y bajas expectativas de vida, la juventud fue concebida como una realidad fugaz y la belleza como algo etéreo. Se resaltó la inexistencia de la belleza material, pues la única belleza existente fue la realidad espiritual. En segundo lugar, dado que en aquella época la miseria afectaba mayormente a la mujeres y son ellas la que se convierten al pentecostalismo, se les concientiza sobre la miseria social y perversidad del mundo; se enfatizó la banalidad de la preocupación corpórea, no solo por su inexistencia, sino también por la opresión somática que a la mujer le tocaba vivir; así, se les insta a la desafección, conminación y discordancia corpórea entre la realidad somática de la sociedad y la presentada por la comunidad pentecostal.

Sin embargo, la mujer joven pentecostal no es un ser pasivo, sino que se resiste y rebela. Por ello, no sólo es necesaria la predicación, sino también la vigilancia sobre los cuerpos jóvenes femeninos. Sin embargo, las jóvenes insisten y no se dejan avasallar por las concepciones pesimistas y deterministas de su comunidad religiosa, y terminan adaptando, conciliando e innovando las concepciones de belleza y fealdad y su relación con el cuerpo y el espíritu.

\section{Referências}

AHUMADA, Jorge. En vez de la miseria. Santiago: Pacifico, 1958.

ALLENDE, Salvador. La realidad médico-social chilena. Ministerio de Salubridad, Previsión y Asistencia Social. Santiago, Chile: Lathrop, 1939.

BENGOA, José. Haciendas y Campesinos. Historia Social de la Agricultura Chilena Tomo II. Haciendas. Santiago, Chile: SUR, 1990.

BROWNING, Webster; RITCHIE, John; GRUBB, Kenneth. The West cost republics of South America. Chile, Perú and Bolivia. London: World Dominion. 1930.

CÓMO SE VIVE en los conventillos de Valparaíso. Revista Zig-Zag, Santiago, n. 691, 18 mayo 1918.

CÓMO VIVE y muere el pueblo en los conventillos. Boletín del Movimiento Pro-Emancipación de las Mujeres de Chile. Revista La mujer nueva, Santiago: El Movimiento, año 1, n. 10, oct. 1936. D'EPINAY, Christian. El refugio de las masas: estudio sociológico del Protestantismo Chileno. Santiago, Chile: Pacifico, 1968.

FRODSHAM, Stanley. With signs following. The story of the Pentecostal revival in the Twentieth Century. Springfield, Missouri: Gospel, 1946.

GALVES, Pedro. Trabajos y antecedentes presentados al Supremo Gobierno de Chile por la Comisión Consultiva del norte. Recopilados por encargo del Ministerio del Interior por Manuel Salas Lavaqueý. Santiago de Chile: Cervantes, 1908.

HURTADO, Alberto. ¿Es Chile un país católico? Santiago: Los Andes, 1941. 
LILLO, Baldomero. Obras Completas. Hugo Álvarez Ignacio y Bello (Ed.). Santiago, Chile: Universidad Alberto Hurtado, 2008.

MARÍN, Eugenia. Condiciones del trabajo de la obrera. Relaciones y documentos del Congreso Mariano Femenino: celebrado en Santiago de Chile, julio de 1918: para conmemorar el Centenario de la Proclamación de la Virgen del Carmen como Patrona Jurada de la República y de su Ejército. Santiago: Esc. Tipo. La Gratitud Nacional, 1918.

MURILLO, Adolfo. La mortalidad urbana en Chile. Santiago, Chile: Roma, 1896.

NAVARRO, Claudia. Las damas porteñas y la moda 1830-1930. ¿Y todas querían ser reinas? Revista del Archivo Histórico Patrimonial de Viña del Mar, año 3, n. 4, 2002.

RADOSLAV, Ivelic. Obra de Arte y Experiencia de lo bello. Aisthesis, n. 27, 1994.

FUEGO DE PENTECOSTES. n. 12, diciembre de 1928.

. n. 99, diciembre de 1936.

SAMUEL GUY, Inman. América Revolucionaria, Conferencias y ensayo. Madrid: Morata, 1933. . América Latina e sua importância mundial. São Paulo: Atlas, 1945.

SIERRA, Luis; MOORE, Eduardo. La mortalidad de los niños en Chile. Valparaíso: Central, 1895. SOLORZA, Susana. Belleza y abyección: la representación del cuerpo femenino en la narrativa de Silvina Ocampo. Revista Espacio, Universidad de Buenos Aires, n. 42, 2009.

TORRES, Isauro. Cómo tener y criar hijos sanos y robustos. Santiago: Nascimiento, 1926.

VERGARA, Marta. Necesidades del control de los nacimientos: el problema del aborto y la mujer obrera. Revista La mujer nueva, Boletín del Movimiento Pro-Emancipación de las Mujeres de Chile, Santiago: El Movimiento, año 1, n. 4, feb. 1936.

WILLEMS, Emilio. Followers of the New Faith: Culture Change and the Rise of Protestantism in Brazil and Chile. Nashville, Tennessee: Vanderbilt University Press, 1967. 